\title{
Correction to: PKM2, function and expression and regulation
}

Ze Zhang ${ }^{1}$, Xinyue Deng ${ }^{2}$, Yuanda Liu ${ }^{3}$, Yahui Liu ${ }^{1 *} \mathbb{0}$, Liankun Sun $^{2^{*}}$ and Fangfang Chen ${ }^{4^{*}}$

\section{Correction to: Cell Biosci (2019) 9:52}

\section{https://doi.org/10.1186/s13578-019-0317-8}

In the publication of this article [1], there is an error in Fig. $7 \mathrm{a}$ and $7 \mathrm{~b}$. This has now been included in this correction.

The error in Figure 7a and 7b:

HMGA2 High Expression HMGA2 Low Expression

Should instead read:

PKM High Expression

PKM Low Expression

The corrected Fig. 7 is given here.

\footnotetext{
*Correspondence: liuyahui2008@yeah.net; sunlk@jlu.edu.cn;

cff@jlu.edu.cn

${ }^{1}$ Department of General Surgery, The First Hospital of Jilin University,

Changchun 130021, China

2 Department of Pathophysiology, College of Basic Medical Sciences, Jilin

University, Changchun 130021, China

${ }^{4}$ Department of Gastrointestinal Colorectal and Anal Surgery, China-

Japan Union Hospital of Jilin University, Changchun 130021, China

Full list of author information is available at the end of the article
} 


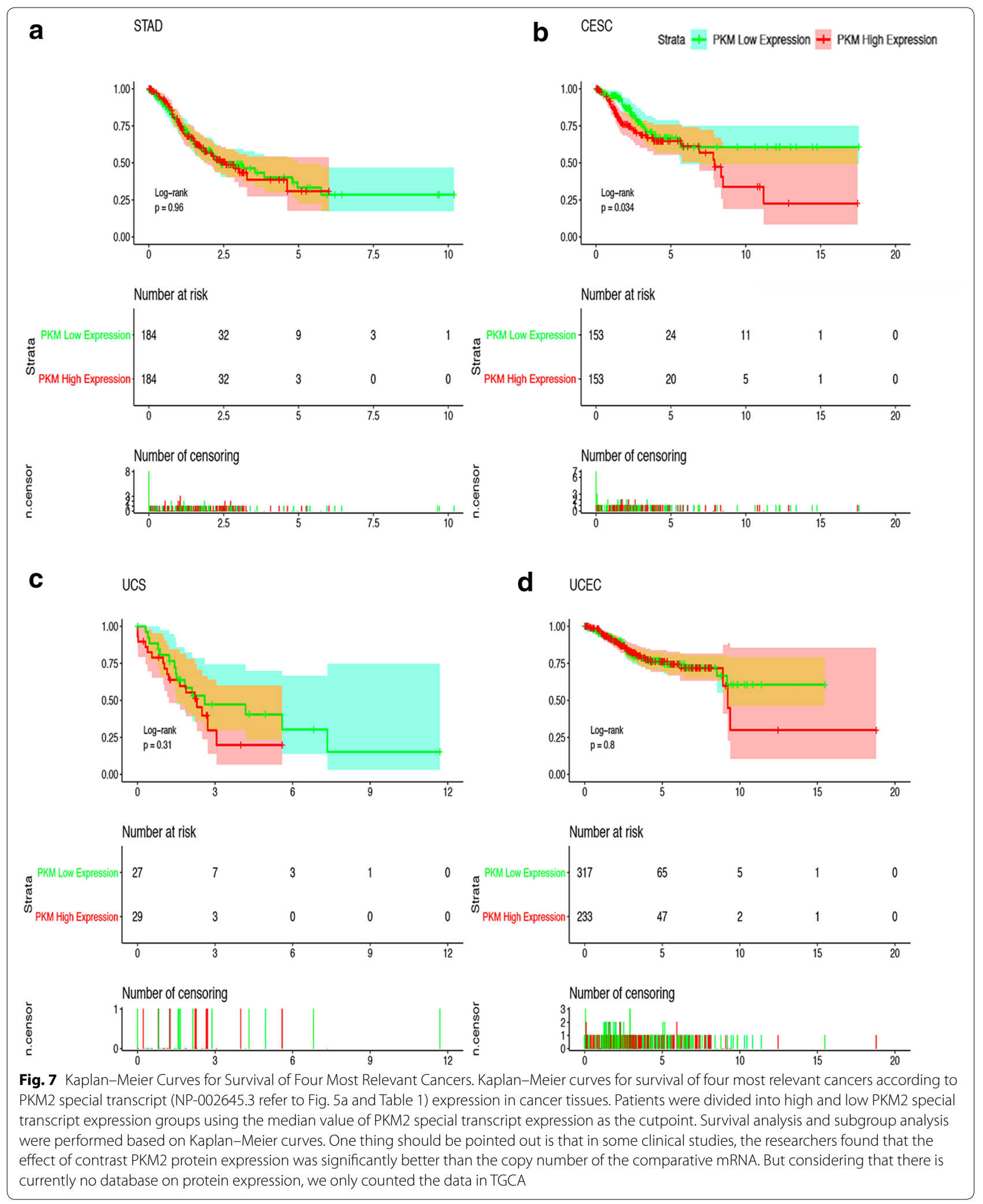




\section{Author details}

${ }^{1}$ Department of General Surgery, The First Hospital of Jilin University,

Changchun 130021, China. ${ }^{2}$ Department of Pathophysiology, College of Basic Medical Sciences, Jilin University, Changchun 130021, China. ${ }^{3}$ Department of Gastrointestinal Surgery, The Second Hospital of Jilin University, Changchun 130041, China. ${ }^{4}$ Department of Gastrointestinal Colorectal and Anal Surgery, China-Japan Union Hospital of Jilin University, Changchun 130021, China.

The original article can be found online at https://doi.org/10.1186/s1357 8-019-0317-8.
Received: 27 June 2019 Accepted: 27 June 2019

Published online: 17 July 2019

\section{Reference}

1. Zhang Z, Deng X, Liu Y, Sun L, Chen F. Cell Biosci. 2019;9:52. https://doi. org/10.1186/s13578-019-0317-8.

\section{Publisher's Note}

Springer Nature remains neutral with regard to jurisdictional claims in published maps and institutional affiliations. 